ISSN 0103-9954

\title{
INCÊNDIOS FLORESTAIS NO PARQUE NACIONAL DA SERRA DA CANASTRA: DESAFIOS PARA A CONSERVAÇÃO DA BIODIVERSIDADE ${ }^{1}$
}

\author{
WILDFIRES IN SERRA DA CANASTRA NATIONAL PARK: CHALLENGES TO BIODIVERSITY \\ CONSERVATION \\ Marcelo Brilhante de Medeiros ${ }^{2}$ Nilton Cezar Fiedler ${ }^{3}$ \\ RESUMO
}

A ocorrência de grandes incêndios florestais em Unidades de Conservação no Brasil pode ser considerada uma grave ameaça para a conservação da biodiversidade e manutenção de processos ecológicos. A propensão ao fogo no Parque Nacional da Serra da Canastra (PNSC), localizado no sul de Minas Gerais, caracterizado pela predominância de vegetação de campos nativos, juntamente com uma cultura de centenas de anos de utilização incorreta de queimadas para manejo agropecuário na região, têm ocasionado incêndios de difícil controle. Esta pesquisa teve como objetivo avaliar as ocorrências de incêndios florestais no Parque Nacional da Serra da Canastra e fornecer subsídios para redução desses índices. Consideramos que esta avaliação deve ter a conservação da biodiversidade como elemento principal de discussão sobre a melhor forma de manejo de fogo para a Unidade de Conservação. A coleta de dados foi feita através da avaliação dos relatórios de ocorrência de incêndios florestais disponíveis na Unidade no período de 1987 a 2001 e visitas de campo. Os resultados mostraram que a maior parte das causas de incêndios no Parque Nacional da Serra da Canastra (50\%) é de origem humana, apesar do grande número de incêndios causados por raios (44\%). Entre as causas humanas, a maior parte é criminosa, originada por incendiários (47\%). Há uma elevada concentração de incêndios causados por raios na estação chuvosa e transição seca-chuva e uma concentração de incêndios de causa humana durante a estação seca, principalmente entre junho e outubro. No entanto, os incêndios de raio normalmente queimam pequenas áreas (menores de $500 \mathrm{ha}$ ), enquanto que os de causa humana são mais catastróficos, atingindo áreas maiores. Para a redução dos incêndios florestais no interior do Parque, é fundamental o controle do fogo através de ações de prevenção, pouco disseminadas na região, principalmente através de educação ambiental e isolamento de combustíveis (aceiros).

Palavras-chave: incêndios florestais; Unidades de Conservação; manejo do fogo.

\section{ASBTRACT}

The Protected Areas in Brazil have been injured by wildfires that treathen the high biodiversity and ecological processes. The Serra da Canastra National Park (SCNP), located at south Minas Gerais State, is characterized by grasslands predominance and an ancient incorrect use of fire as a land management tool, wich cause large wildfires. The objective of this work was to analyse fire ocorrences in SCNP and to give data to reduce large wildfires as a biodiversity conservation question. The data collection was carried out with fire reports from 1987 to 2001 and local visits. The results shown that most of forest fires causes (50\%) in SCNP are human originated, in spite of several forest fires caused by lightnings (44\%). Among human causes the most is originated by lawbreakers (47\%). There is a high number of forest fires caused by lightnings during the rainy season and transition dry-rainy season and a high number of forest fires caused by humans during the dry season. However, the forest fires caused by lightnings are often restricted to small areas (lower than $500 \mathrm{ha}$ ) and the forest fires caused by humans reached large areas in SCNP. Furthermore, the control of fire in SCNP should include several prevention activities, mainly environmental education and combustible isolation.

Key words: wildfires, fire management, protected areas.

\section{INTRODUÇÃO}

No Brasil, as causas dos incêndios florestais nas Unidades de Conservação têm sido principalmente

1. Trabalho realizado em consultoria ao Instituto Terra Brasilis, através do projeto de Revisão do Plano de Manejo do Parque Nacional da Serra da Canastra, sob demanda do IBAMA, financiado pelo Consórcio UHE Igarapava.

2. Biólogo, Dr., Pesquisador III da Embrapa Recursos Genéticos e Biotecnologia, Prédio de Coleta e Caracterização, Av. W3 Norte, s/n., Caixa Postal 02372, CEP 70770-900, Brasília (DF).

3. Engenheiro Florestal, Dr., Professor Adjunto do Departamento de Engenharia Florestal, Universidade de Brasília, Asa Norte, Caixa Postal 152.958, CEP 79919-970, Brasília (DF). fiedler@unb.br

Recebido para publicação em 11/01/2003 e aceito em 1/12/2003. 
devido ao uso incorreto do fogo por pessoas, para renovação de pastagens e limpeza de restos de cultura nas propriedades vizinhas. Neste sentido, freqüentemente não são realizados aceiros, as condições climáticas não são verificadas, o período da realização da queima é inadequado e há desconhecimento sobre equipamentos de controle do fogo e alternativas ao uso de queimadas. Além disso, são também causas freqüentes a ação de incendiários, caçadores, pescadores e soltura de balões, entre outras (Medeiros, 2002a).

A ocorrência de grandes incêndios florestais em Unidades de Conservação pode ser considerada uma grave ameaça para a conservação da biodiversidade e manutenção de processos ecológicos. Estes incêndios são particularmente graves para áreas pequenas, em ecossistemas muito sensíveis ao fogo, áreas isoladas por cidades ou monoculturas agrícolas e áreas com espécies raras e/ou ameaçadas de extinção. Nestas áreas, há maior possibilidade de grandes incêndios comprometerem a manutenção de populações de algumas espécies. Deve-se considerar ainda que grande parte das Unidades de Conservação no Brasil apresenta uma ou mais destas características vulneráveis.

Nas últimas décadas, com a crescente ocupação e conversão do cerrado em áreas agrícolas, as Unidades de Conservação localizadas neste bioma têm sido constantemente impactadas pela ação freqüente de incêndios florestais.

No cerrado brasileiro, a ocorrência de fogo é um fenômeno antigo, o que é evidenciado pela existência de amostras de carvão datadas entre 27.100 a 41.700 anos antes do presente (AP) (Vicentini, 1993). Entre cerca de 18.000 a 773 anos antes do presente, Vicentini (1999) também observou que as queimadas ocorriam em uma freqüência menor que a atual para o cerrado, atingindo, porém, grandes áreas.

Antes da colonização pelos europeus, os índios já utilizavam e ainda utilizam o fogo em áreas de cerrado como ferramenta de manejo para caça e seleção de espécies alimentícias (Posey, 1987; Lévi-Strauss, 1996). Algumas técnicas de controle do fogo, como a utilização de aceiros, também já eram praticadas por grupos indígenas na região.

Com a colonização nas áreas de cerrado, o índio e seu modo de vida foram sendo substituídos pelo sistema econômico europeu, o qual introduziu o gado na região como atividade econômica principal, além dos garimpos. Nesta época, já havia registros sobre a ocorrência de incêndios, como na região de Serra da Canastra, onde ainda no século XIX, Saint Hilaire (1986) já descrevia a elevada frequência de incêndios, em grandes áreas e em diferentes épocas do ano, para renovação de pastagens para o gado. Nesta época, os incêndios possivelmente tornaram-se mais intensos, ocorrendo principalmente no final da seca, em contraste com as queimadas menos intensas para manejo dos indígenas, as quais ocorriam antes do final da seca para permitir a frutificação de algumas espécies (Posey, 1987; Dias 1998). As queimadas naturais provocadas por raios também são geralmente menos intensas, porque ocorrem em condições mais úmidas.

No período entre 1600 até a década de 1960, a frequência de fogo no cerrado passou a ser bienal/anual para a renovação de pastagens, no final da estação seca. Nos últimos 30 anos, com o aumento populacional e as atividades florestais e agropecuárias, a freqüência de fogo aumentou (Dias, 1998). Atualmente, na mesma região da Serra da Canastra descrita por Saint-Hilaire (1986), as queimadas descontroladas continuam freqüentes, ocorrendo principalmente no final da estação seca e atingindo grandes áreas, com o agravante de um maior adensamento populacional na região (Fiedler e Medeiros, 2002).

O regime de fogo é conceituado como o padrão de intensidade, freqüência e sazonalidade deste elemento em uma área (Agee, 1993). Devido às mudanças que ocorreram no cerrado, envolvendo vários componentes do ecossistema, é problemático aplicar regimes de fogo históricos, considerando os raios e as queimadas para manejo dos indígenas do passado, porque as respostas aos distúrbios podem ser diferentes do padrão anterior (Whelan, 1997). Fatores "naturais," como incêndios provocados por raios, e fatores antropogênicos interagem, tornando dificil identificar, isolar ou quantificar os determinantes da estrutura destes ecossistemas (Scholes e Archer, 1997).

Isto pode ocorrer porque as áreas de cerrado sofreram mudanças em seus componentes biológicos ao longo do tempo, com variações na composição e estrutura das comunidades. O que era há 3000 anos uma vasta extensão de cerrado, hoje se reduziu a fragmentos isolados, que sofrem variados distúrbios causados por atividades antrópicas no entorno que não ocorriam anteriormente na mesma escala e/ou tipo (Medeiros, 2002a). 
Assim, a aplicação de regimes de fogo (queimadas controladas) ou de supressão em áreas de cerrado depende fundamentalmente de pesquisas sobre os efeitos do fogo na biota, as quais já identificaram algumas características adaptativas e, também, efeitos adversos derivados do atual regime de fogo.

Entre as características que suportam a idéia de estratégias adaptativas da vegetação do cerrado ao fogo, há forte suberização do tronco e dos galhos, permitindo certo grau de isolamento térmico dos tecidos internos, mesmo em temperaturas elevadas (Guedes, 1993; Coutinho, 1990), e, também, ocorrem frutos com capacidade de proteção das sementes (Landim e Hay, 1995). Já foram verificados efeitos positivos do fogo sobre o sucesso reprodutivo de algumas espécies (Silva et al., 1996) e sobre a dispersão de sementes (Coutinho, 1977). As gemas apicais de algumas espécies também podem estar protegidas através de catáfilos (Coutinho, 1990). Entre as espécies lenhosas, é comum a capacidade de rebrota através da copa, rizomas, caule, raiz e estruturas subterrâneas (Souza e Soares, 1983; Medeiros, 2002b).

Entre os efeitos adversos de queimadas freqüentes para a flora lenhosa, já foram constatados a diminuição da densidade arbórea, como conseqüência da redução do recrutamento de árvores, e o aumento do entouceiramento (Ramos, 1990), além da diminuição da diversidade de espécies (Sambuichi, 1991). Silva (1999), Sato (1996) e Medeiros (2002b) verificaram elevadas taxas de mortalidade em campo sujo e cerrado sensu stricto após queimadas prescritas. Em fitofisionomias florestais, como cerradão, o fogo pode eliminar muitos indivíduos, tornando este tipo de formação mais rala em termos de elementos lenhosos (Souza e Soares, 1983). Também já foram verificados impactos negativos sobre a reprodução sexual através da destruição de estruturas reprodutivas (frutos, flores, sementes) (Hoffmann, 1998).

A propensão ao fogo no PNSC, caracterizada pela predominância de vegetação de campos, juntamente com uma cultura de centenas de anos de utilização incorreta de queimadas para manejo agropecuário na região, têm ocasionado incêndios de difícil controle.

Basicamente, o manejo de fogo em uma Unidade de Conservação deve levar em conta as seguintes considerações (Robbins e Myers, 1992; Gill, 1994): a resposta natural do ecossistema ao regime de fogo proposto; os efeitos dos diferentes regimes de fogo sobre a biota e processos ecológicos; a importância do fogo para a biota e para os processos ecológicos.

Esta pesquisa teve como objetivo avaliar as ocorrências de incêndios florestais no PNSC e fornecer subsídios para a redução desses índices.

\section{REGIME DE FOGO NO PNSC}

O PNSC foi criado em 3 de abril de 1972, através do Decreto $n^{\circ} 70.355$, e está situado na região sudoeste do Estado de Minas Gerais, nos municípios de São Roque de Minas, Sacramento, Delfinópolis, São João Batista do Glória, Capitólio e Vargem Bonita, compreendendo uma área de aproximadamente 200.000 hectares. Da área decretada do PNSC, 71.525 ha estão com a situação fundiária regularizada (chapadão da Canastra), ou seja, sob posse e domínio do Instituto Brasileiro do Meio Ambiente e dos Recursos Naturais Renováveis (IBAMA). O restante da área decretada e ainda não regularizada é constituído por propriedades privadas, sendo denominado Chapadão da Babilônia.

Os dados sobre a ocorrência de incêndios na região são coletados pelos funcionários do IBAMA sistematicamente desde 1987, através de relatórios de ocorrência de incêndios. Para a caracterização do regime de fogo no PNSC, foram analisados os dados referentes ao período de 1987 a 2001 dos relatórios. No entanto, os registros sobre ocorrência de incêndios disponíveis na sede da Unidade se referem apenas à área do Chapadão da Canastra (71.525 ha). Os dados analisados nos relatórios incluíram: causas de incêndios, área queimada e datas de ocorrência.

A maior parte das causas de incêndios no PNSC, desde 1987, é de origem humana, apesar do grande número de incêndios causados por raios, os chamados incêndios naturais (Figura 1). 


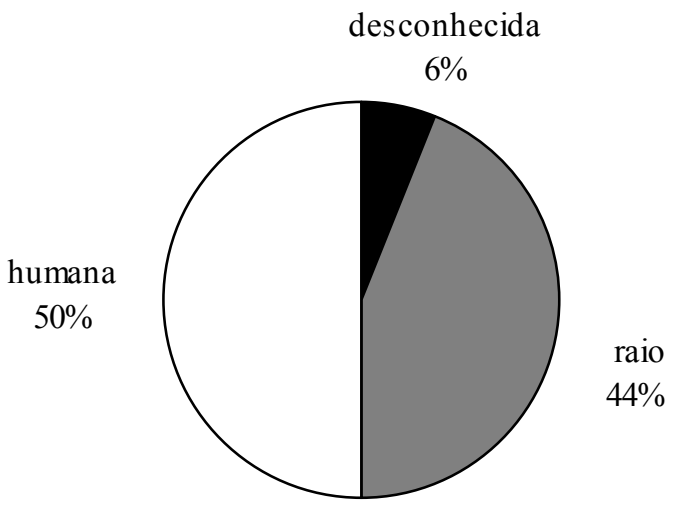

FIGURA 1: Causas de incêndios florestais no Parque Nacional da Serra da Canastra, no período de 19872001. (Total de incêndios $=87$ ).

FIGURE 1: Forest fires causes in Serra da Canastra National Park, from 1987 to 2001. (Number of forest fires $=87$ ).

Alguns estudos em Unidades de Conservação em áreas de cerrado verificaram frequência elevada de incêndios causados por raios (Ramos-Neto, 2000; Medeiros, 2002a), distúrbio este que, teoricamente, pode beneficiar a diversidade de espécies. Distúrbios naturais, como o fogo são eventos rápidos que causam mudanças em comunidades, espécies, populações e disponibilidade de recursos. Ocorrendo habitualmente em certas comunidades naturais, este tipo de distúrbio é fundamental para a ecologia de tais sistemas, estando as espécies que ocorrem nestes ambientes adaptadas a um específico "regime de distúrbio," considerando freqüência, intensidade e extensão dos eventos que ocorrem em uma área. De forma natural, estes distúrbios são pequenos e pouco destrutivos, enquanto eventos de grande magnitude são mais raros. Quando o distúrbio é alterado substancialmente, as comunidades podem mudar para um sistema completamente diferente (Pickett e White, 1985). Assim, em algumas situações, os distúrbios naturais podem ser requeridos ou limitados por ações de manejo para manter os ecossistemas naturais (Agee, 1993).

Os raios são uma das principais fontes de ignição em savanas, nas quais a extensão da estação seca transforma o componente herbáceo propenso ao fogo (Stocks e Trollope, 1993).

As queimas provocadas por raios têm sido consideradas como um distúrbio que pode auxiliar na conservação da biodiversidade e como natural em alguns ecossistemas propensos ao fogo (Komarek, 1972; Middleton et al., 1997).

Em áreas de cerrado, poucos dados sobre queimas provocadas por raios foram registrados e analisados, excetuando-se nos Parque Nacionais de Emas (GO) (Ramos-Neto, 2000) e nos Parques Nacionais de Serra da Canastra e Chapada dos Veadeiros (Medeiros, 2002a). No Parque Nacional das Emas, as áreas queimadas apresentaram uma média anual de 20.000 ha, entre 1996 e 1999, sendo que grande parte destes incêndios foram causados por raios. Foram identificadas 45 queimas neste período, sendo 4 na estação seca, 10 na transição seca-chuva e 31 durante a estação chuvosa. Deste total, 5 queimas foram antropogênicas e 40 causadas por raios (setembro a maio). As queimas naturais, porém, são pequenas e apresentaram uma área média de 500 ha (Ramos-Neto, 2000), padrão similar ao encontrado no Parque Nacional da Serra da Canastra.

Entre as causas humanas, a maior parte é criminosa, originada por incendiários (Figura 2). O grande número de incêndios desta natureza no Parque é problemático devido à complexidade de motivos que levam o indivíduo a cometer esses atos criminosos. A redução de incêndios desta natureza deve acontecer com o fortalecimento de ações preventivas e inibitórias combinadas (educação ambiental, fiscalização). 


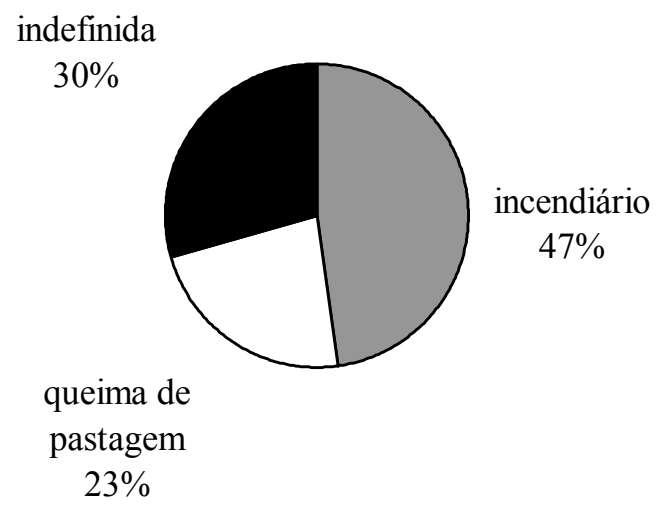

FIGURA 2: Distribuição de causas de incêndios florestais de origem humana no Parque Nacional da Serra da Canastra, no período de 1987-2001. (Total de incêndios $=87$ ).

FIGURE 2: Distribution of forest fires causes from human ativities in Serra da Canastra National Park, from 1987 to 2001. (Number of forest fires $=87$ ).

O uso do fogo como ferramenta de manejo agropecuário também é causa importante de incêndios na região (Figura 2). Embora muitos fazendeiros da região declarem a realização de aceiros para controlar os incêndios (Printes e Santos-Silva, 1998), aparentemente esta prática não tem sido eficiente. Além disso, não há conhecimento, nas fazendas, de técnicas específicas de controle de queimadas, equipamentos adequados, horários mais favoráveis e um calendário de queima. De forma geral, técnicas alternativas ao uso do fogo também não são disponibilizadas na região.

Deve-se considerar também que praticamente não ocorreram perícias nos incêndios que aconteceram no Parque. Assim, entre os incêndios de causa humana indefinida, provavelmente há muitos com origem nas fazendas do entorno, considerando a prática disseminada do uso do fogo na região para renovação de pastagens, geralmente com freqüência bienal em cada propriedade rural (Printes e Santos-Silva, 1998).

A distribuição dos incêndios ao longo dos anos mostra um padrão conhecido de incêndios causados por raios na estação chuvosa e transição seca-chuva (setembro a abril) e uma concentração de incêndios de causa humana durante a estação seca, principalmente entre junho e outubro (Figura 3).

A principal característica do regime de fogo em Unidades de Conservação, como o PNSC e Emas, seria a existência de um regime de causas antrópicas, na época seca, e de um regime de causas naturais (raios), na transição seca-chuva e na estação chuvosa.

Os dados sobre os efeitos das queimadas naturais são esparsos, havendo apenas indicativos de que sua ocorrência torna as comunidades herbáceas mais heterogêneas (Ramos-Neto, 2000). Como distúrbios naturais que ocorrem a milhares de anos, é provável que sejam fundamentais para o ecossistema. Assim, apenas teoricamente, essas queimadas provocadas por raios podem ser benéficas para a biota do cerrado, formando comunidades mais heterogêneas, devendo ser combatidas no PNSC apenas se a chuva não extinguir os focos, com a possibilidade de tornar-se um incêndio de grandes dimensões, e em caso de atingir áreas de proteção (fisionomias florestais e/ou de cerrado mais denso, locais de pesquisa, áreas de refúgio e reprodução de espécies, benfeitorias, etc). De qualquer forma, pesquisas devem ser realizadas para verificação dos efeitos dessas queimas. 


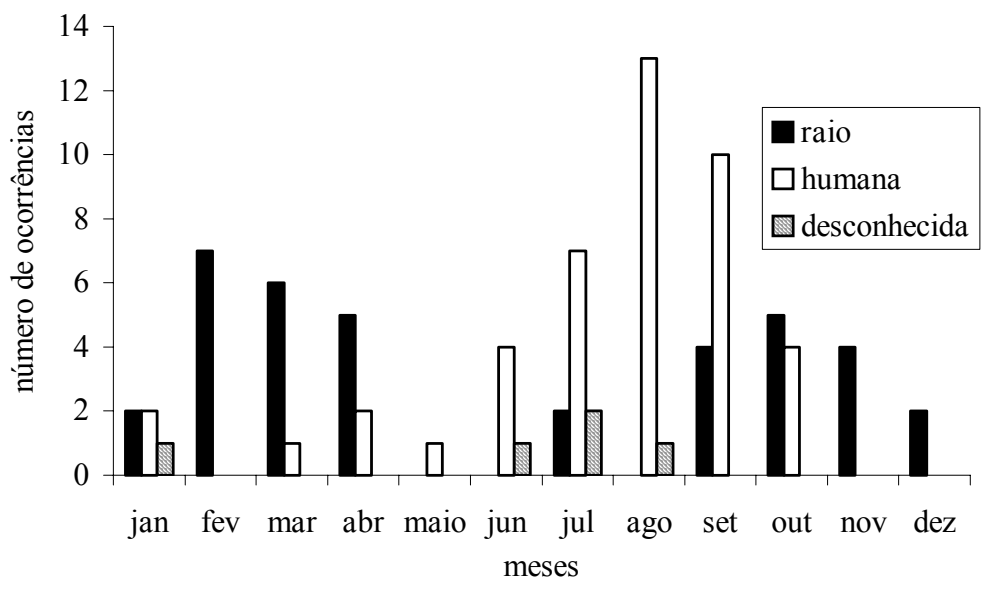

FIGURA 3: Distribuição do número de ocorrências e causas de incêndios florestais durante os meses de janeiro a dezembro, no Parque Nacional da Serra da Canastra, no período de 1987-2001.

FIGURE 3: Distribution of number and causes of forest fires by month in Serra da Canastra National Park, from 1987 to 2001.

A distribuição de classes de área atingida por tipo de incêndio florestal no PNSC também mostra um padrão conhecido, no qual geralmente os raios causam pequenos incêndios (menos de 500 ha), e os incêndios de causa humana são responsáveis pelos de grande magnitude (Figura 4). Este padrão ocorre também em outras Unidades de Conservação no cerrado, como os Parques Nacionais de Emas (Ramos - Neto, 2000) e a Chapada dos Veadeiros (Medeiros, 2002a).

Normalmente, após os raios, as chuvas extinguem os focos de incêndios, limitando-os a pequenas áreas e com menor impacto ambiental. Em alguns poucos casos, a chuva não atinge o local, e o incêndio pode se tornar de grande porte.

Os incêndios de causa humana, normalmente durante a estação seca, encontram as condições propícias (vegetação seca, umidade relativa baixa, ventos fortes) ao desenvolvimento de incêndios de grandes magnitudes.

Em alguns casos, os incêndios de causa humana queimaram quase todo o Parque. Muitos incêndios de causa humana foram contidos em áreas menores do que 500 ha devido à ação rápida dos brigadistas.

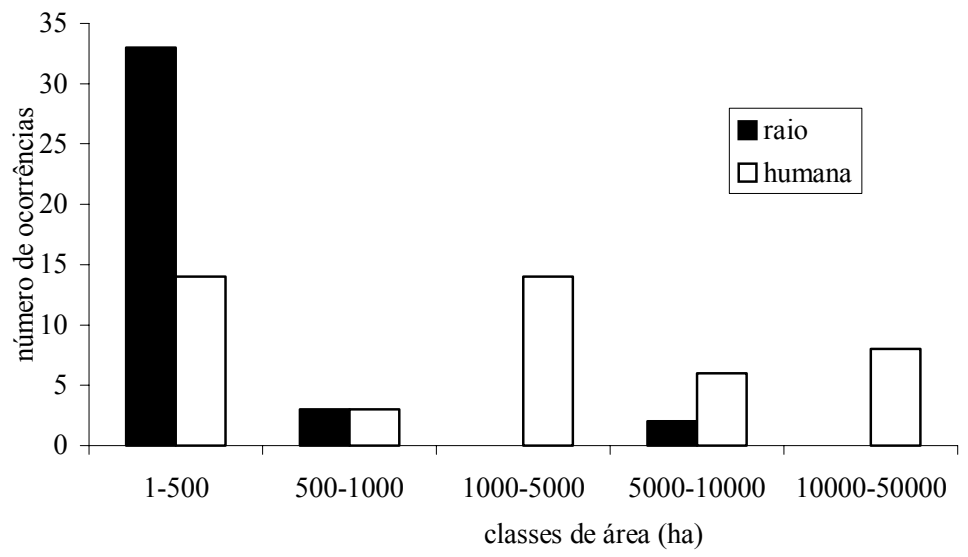

FIGURA 4: Classes de tamanho de área queimada em relação às causas de incêndios no Parque Nacional da Serra da Canastra, no período de 1987-2001.

FIGURE 4: Size classes related to burnt areas and forest fires causes in Serra da Canastra National Park, from 1987 to 2001 . 
O PNSC tem sofrido incêndios florestais de grandes dimensões em uma freqüência anual/bienal (Figura 5). Considerando que os grandes incêndios no Parque têm ocorrido no auge ou no final da estação seca, as condições climáticas (temperatura mais elevada no final de agosto/setembro, com baixa umidade e ventos fortes, e a vegetação mais seca) propiciam condições para queimas de maior intensidade do que em outras épocas do ano. Em áreas de Cerrado, Miranda et al. (1996) verificou que os incêndios no final da estação seca apresentam maior intensidade. Deste modo, o regime de fogo no PNSC é caracterizado pela elevada freqüência de grandes incêndios, provavelmente de maiores intensidades durante a estação seca devido às condições climáticas, e uma freqüência um pouco menor de incêndios naturais em áreas menores, durante a estação chuvosa e transição seca-chuva.

A escala de impactos causados pelos grandes incêndios de causa humana provavelmente está afetando elementos da biota na Unidade, já fragilizados por outros impactos provenientes do entorno, como alteração da qualidade de água dos rios, desmatamentos, urbanização, etc.

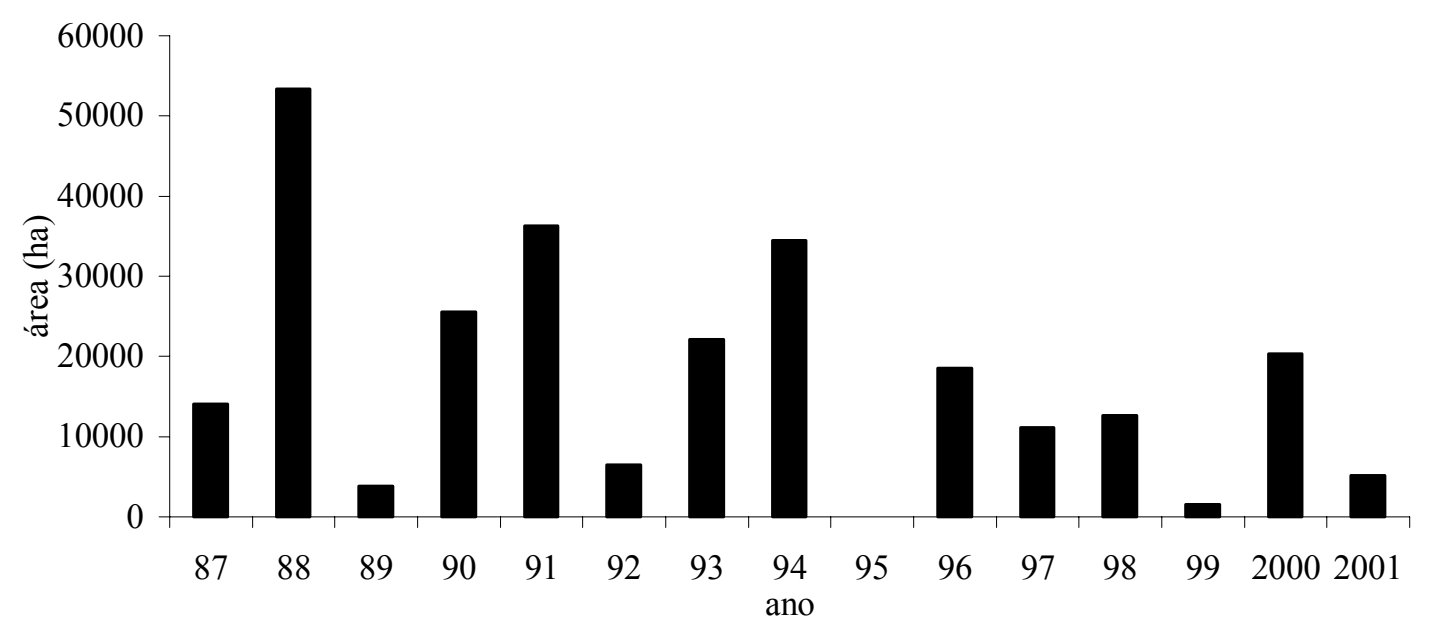

FIGURA 5: Distribuição de áreas queimadas em relação aos anos no Parque Nacional da Serra da Canastra, no período de 1987-2001.

FIGURE 5: Burnt areas by year in Serra da Canastra National Park, from 1987 to 2001.

Para a área não considerada nestes registros, ou seja, 128.425 há, os quais estão sendo incorporados, é possível apenas algumas inferências de acordo com informações de funcionários, moradores da região e análise da vegetação, topografia, hidrografia e atividades econômicas no entorno.

Esta área, não-indenizada, ainda está sendo utilizada em atividades agropecuárias e de mineração. Nas áreas de chapada, predomina a pecuária, com utilização de campos nativos, enquanto nos vales, praticase agricultura e pecuária com um maior grau de alteração na vegetação.

As observações indicam que não há, nas fazendas desta área e no entorno, conhecimento e utilização de técnicas adequadas de queima controlada, e que também, os produtores não possuem equipamentos específicos para o combate ao fogo.

Nesta área, não existem atividades de combate sistemáticas, e, muitas vezes, o fogo atravessa diversas fazendas antes de ser barrado por estradas, rios, afloramentos rochosos, chuvas ou combates esporádicos de alguns moradores.

Com base nessas características e pelas informações coletadas, conclui-se que existe, nesta região, uma elevada freqüência de ocorrência de incêndios florestais, atingindo áreas significativas e levando a danos consideráveis tanto em termos ambientais quanto econômicos, principalmente no meio e no final da estação seca. As queimadas provocadas por raios também são freqüentes. No entanto, atingem áreas menores.

O regime de fogo, portanto, é similar à área anteriormente considerada, com o agravante de não existirem atividades sistemáticas de prevenção e combate. 
Particularmente, a vegetação de campo, predominante no Parque, na estação seca, torna-se bastante propensa ao fogo, transformando-se em uma camada de material morto acima do solo. Abaixo do solo, os tecidos vivos das plantas herbáceas ficam protegidos das chamas, caracterizando uma vegetação bastante adaptada a incêndios (Rosa, 1990).

O crescente isolamento das Unidades de Conservação do cerrado, entre outras graves ameaças, tem diminuído a possibilidade de corredores ecológicos e pode agravar o impacto negativo do fogo sobre várias espécies animais com populações reduzidas (Medeiros, 2002a).

Ainda há carência de dados locais sobre os efeitos do fogo para vários grupos de animais como insetos, répteis, aves e anfíbios, e deve-se evitar a generalização de resultados de pesquisas devido às características peculiares de cada Unidade de Conservação.

Para diminuir a ocorrência dos incêndios e estabelecer um regime de fogo ou supressão benéfico para a biota, as atividades de manejo de fogo no PNSC devem incluir um planejamento amplo, abrangendo componentes de pré-supressão aos incêndios, de caráter preventivo, como: educação ambiental, recrutamento e treinamento de brigadas civis de combate aos incêndios, suprimento de equipamentos específicos para combate aos incêndios florestais, sistemas de análise de risco de incêndios como, por exemplo, através de modelos de combustível, sistemas de detecção de focos e de comunicação e manejo de combustíveis (aceiros, queimadas naturais). Além disso, devem ser desenvolvidas estratégias de supressão ou combate aos incêndios e um programa de monitoramento de todas as atividades através de pesquisas e procedimentos técnicos.

A seguir, descrevemos alguns destes componentes analisados no PNSC que consideramos fundamentais para a implantação de um projeto de redução de incêndios florestais nesta Unidade de Conservação.

\section{PROPOSTAS PARA O SISTEMA DE PREVENÇ̃̃O DE INCÊNDIOS FLORESTAIS NO PNSC}

\section{Sistema de aceiros}

A execução de aceiros externos ou internos para barrar a propagação de incêndios nas UC é um assunto bastante discutido entre os especialistas e no meio conservacionista. As principais críticas ao uso de aceiros com fogo (negros) se referem principalmente ao aumento de mortalidade de árvores nas faixas aceiradas, exposição da fauna herbívora nos limites externos e aumento da invasão por espécies exóticas de gramíneas. De forma geral, não se conhecem pesquisas sobre o efeito ecológico dos aceiros nas Unidades de Conservação.

Em algumas UC do Cerrado, como os Parques Nacionais de Emas, Chapada dos Veadeiros, Sete Cidades e Brasília, a execução de aceiros externos e internos tem diminuído de modo significativo a frequência e a extensão das áreas atingidas, sendo fundamentais para a quebra dos ciclos de grandes incêndios que ocorriam com intervalos de três/quatro anos. Estes aceiros são executados através de queima anual de uma faixa de vegetação de largura entre 25 e 60 metros.

No PNSC, as estradas/aceiros no Chapadão da Canastra têm causado uma diminuição na velocidade de propagação do fogo em alguns trechos e, em alguns casos, barram a continuidade dos incêndios.

No Chapadão da Canastra, há uma estrada de terra com cerca de 5 metros de largura que atravessa a chapada, ligando a portaria 1 até a portaria 3, com uma extensão de $60 \mathrm{~km}$. Algumas estradas de terra perpendiculares a esta, seguem em direção ao norte do Parque, totalizando aproximadamente $30 \mathrm{~km}$ de extensão. Estas estradas não possuem uma faixa de alargamento com uso do fogo, o chamado aceiro negro, reduzindo assim a eficiência das mesmas na contenção da propagação de incêndios de alta velocidade.

Embora seja uma ferramenta eficiente para contenção de incêndios em várias UC, a realização de aceiros é uma atividade com risco de descontrole do fogo, e há impactos nos recursos naturais que devem ser minimizados e monitorados como, por exemplo, a seleção de espécies herbáceas mais resistentes ao fogo nas faixas queimadas.

No PNSC, deve ser desenvolvido um programa de pesquisas para avaliar a continuidade dos aceiros atuais, dos aceiros negros e a possibilidade de execução de aceiros na área do Chapadão da Babilônia. Este programa deve mapear e estudar as comunidades de fauna e flora ao longo das estradas que seriam aceiradas. Este mapeamento teria por objetivo evitar impactos dos aceiros sobre grupos sensíveis ao fogo, 
espécies raras, endêmicas e/ou ameaçadas de extinção. Além disso, as pesquisas devem avaliar o impacto de queimadas freqüentes sobre os componentes da flora e fauna.

\section{Sistema de detecção/comunicação}

De acordo com informações dos funcionários, a grande maioria dos incêndios no PNSC é detectada menos de uma hora após seu início, considerando apenas a área do Chapadão da Canastra. Porém, em áreas de cerrado, nas quais a velocidade do fogo normalmente é rápida, a detecção de incêndios idealmente não deve ultrapassar 5 minutos.

Assim, o tempo de detecção atual na área do Chapadão da Canastra não é adequado, pois o sistema de observação desta área apresenta deficiências, como a falta de observadores (torristas) e goniômetros. Os focos de incêndio são normalmente detectados quando a coluna de fumaça está grande o suficiente para ser observada de portarias, centro de visitantes ou estradas internas e externas. A frente de fogo, nestes casos, também já assumiu grandes proporções.

O sistema de detecção deve ter como padrão características que incluam a rápida localização dos focos e a precisão dessa localização. Além disso, o sistema de detecção deve abranger os períodos diurno e noturno, e a localização dos focos idealmente deve ocorrer sobre quaisquer condições de visibilidade.

Torres de observação, guaritas dotadas de goniômetros e rádio comunicação e veículos para as rondas são freqüentemente utilizados como sistemas de detecção em UC e áreas de reflorestamento.

Apesar do custo inicial relativamente elevado, as torres de observação apresentam um custo mais reduzido, comparado ao uso de aeronaves ou câmeras com sensores infra-vermelho.

A eficiência e complementação do sistema de deteç̧ão com torres e guaritas depende de observadores treinados para permanência diurna e noturna, equipamentos de rádio-comunicação, binóculos e equipamentos para localização precisa dos focos (goniômetros e mapas).

O sistema de detecção existente no PNSC na região do Chapadão da Canastra é composto de uma torre de observação, duas guaritas de observação, três portarias e patrulhas com veículos. A região do Chapadão da Babilônia não dispõe de sistema de detecção.

A torre e as guaritas de observação do PNSC, localizados em pontos mais elevados na região do Chapadão da Canastra, proporcionam uma boa visibilidade do interior e entorno desta área e constituem os elementos mais importantes no sistema de detecção. Entretanto, a torre de observação não está sendo utilizada porque a base de madeira está comprometida, não há escadas de segurança e as condições da cabine aparentemente são precárias. Da mesma forma, os pontos de observação com pequena estrutura (Bentinho e Serra Brava) não estão sendo utilizados permanentemente devido à falta de estrutura (rádios, goniômetros).

Atualmente, o PNSC tem obtido informações de detecção de focos de calor através de satélites da série NOAA. Estes dados são disponibilizados diariamente através do Instituto Nacional de Pesquisas Espaciais (INPE) e enviados para o IBAMA sede. Este tipo de detecção tem sido muito importante principalmente devido à dimensão do Parque e ao alcance nas áreas de entorno. A principal desvantagem deste sistema é observada na transmissão de informação, pois os dados são recebidos em Brasília no final do dia e disponibilizados apenas no dia seguinte.

\section{Educação ambiental}

De acordo com os dados levantados, não há atividades sistemáticas de educação ambiental dirigida para o público enfocando a questão dos incêndios florestais no PNSC.

A elevada incidência de incendiários atuando no PNSC deve ser minimizada através de ações educativas, enfocando principalmente, a importância da UC no contexto sócio-ambiental e o estabelecimento de vínculos com as comunidades do entorno.

As atividades educativas devem ser dirigidas às comunidades do entorno, pelo fato dessas utilizarem o fogo como ferramenta de manejo agropecuário e proporcionar queimadas descontroladas que causariam os principais incêndios no PNSC.

As atividades preventivas para controle do fogo em áreas rurais têm sido mais eficientes quando as comunidades são orientadas em um trabalho local, com contatos diretos entre técnicos e produtores. $\mathrm{Na}$ 
Amazônia, algumas comunidades de pequenos produtores têm sido orientadas localmente desta forma, com resultados bastante positivos (Nepstad et al., 1999).

A distribuição esporádica de cartazes, cartilhas e "folders," divulgando o problema e formas de contato com a Unidade, geralmente tem público e alcance limitados, considerando a realidade do meio rural brasileiro em relação aos níveis de escolaridade. Da mesma forma, campanhas educativas transmitidas pela televisão, de custo elevado, também têm alcance limitado, considerando pequenos produtores rurais que não tem acesso a esta mídia, como ocorre em várias regiões do país. Além disso, as campanhas televisivas não são suficientes para trazer aos produtores detalhes sobre como realizar as queimadas, os impactos do fogo, técnicas de substituição deste procedimento e as possibilidades de diminuição dos custos associadas à execução de aceiros e de equipamentos básicos de combate.

As atividades de educação ambiental devem ser fundamentadas principalmente em palestras e visitas programadas à UC. O investimento neste tipo de atividade geralmente é bastante reduzido em relação aos custos das operações de combate aos incêndios.

A prevenção de incêndios no PNSC pode ser também baseada em cursos específicos de queima controlada e sobre técnicas alternativas ao uso do fogo.

\section{Queimadas controladas}

Um dos itens mais polêmicos em relação ao planejamento do uso de fogo diz respeito ao manejo de combustíveis, particularmente quando são propostas queimadas controladas como tentativa de restabelecer padrões de distúrbio para a conservação de uma área (Medeiros, 2002a). O uso de queimadas controladas unicamente como forma de redução de combustíveis para controle do fogo pode não ser compatível com estes objetivos se pesquisas sobre os efeitos do fogo na biota local não forem realizadas. Assim, a redução de combustíveis não deve ser o único objetivo de queimadas controladas quando a prioridade é a conservação dos recursos naturais (Stocks e Trollope, 1993).

O fogo, utilizado na forma de queimadas controladas, pode ser considerado como ferramenta de auxílio à conservação em áreas abertas de cerrado, como o PNSC. Porém, de modo geral, ainda há escassez de dados de pesquisa sobre os ecossistemas nas Unidades de Conservação no Brasil e os efeitos do fogo sobre a biota local do PNSC. A possível utilização de queimadas controladas deve ser baseada fundamentalmente em dados de pesquisa que comprovem o benefício desta ferramenta de manejo para a conservação dos recursos. Além disso, deve ser avaliado detalhadamente o papel de queimas provocadas por raios na área considerada. Assim, um programa de pesquisa multidisciplinar deveria ser implantado no PNSC para a realização de pesquisas de longa duração.

Em uma Unidade de Conservação, como o PNSC, onde há invasão de espécies exóticas de plantas e animais, juntamente com vários processos de degradação ambiental no entorno que podem afetar a biota dentro do Parque, torna-se bastante difícil a aplicação de técnicas de manejo sem um embasamento científico consolidado.

\section{CONCLUSÕES}

O Parque Nacional da Serra da Canastra apresenta um padrão com elevada freqüência de incêndios de causa humana, atingindo grandes áreas, na estação seca, e incêndios de causa natural, atingindo geralmente áreas pequenas na estação chuvosa e transição seca-chuva.

O grande desafio de manejo do fogo nesta Unidade de Conservação ou de estabelecimento de planejamento de prevenção e combate aos incêndios florestais é entender quais os efeitos do fogo, natural e de causa antrópica, sobre os recursos naturais e também os efeitos da exclusão do fogo sobre os vários componentes da biota. Embora teoricamente as queimadas provocadas por raios possam trazer benefícios ao propiciar condições mais heterogêneas para a vegetação herbácea, não há pesquisas locais suficientes para estabelecer procedimentos.

É fundamental, primeiramente, a implantação de ações para o controle dos grandes incêndios na região. Alguns pontos para alcançar este objetivo precisam ser desenvolvidos prioritariamente, como ações de educação ambiental, execução de aceiros e implantação de sistemas de detecção/comunicação. 


\section{AGRADECIMENTOS}

Os autores agradecem as informações e o apoio disponibilizados pelo IBAMA, Instituto Terra Brasilis, chefe e demais funcionários do PNSC e agricultores do entorno para a realização deste trabalho.

\section{REFERÊNCIAS BIBLIOGRAFICAS}

AGEE, J. K. Fire Ecology of Pacific Northwest Forests. New York: Island Press, 1993.

COUTINHO, L. M. Aspectos ecológicos do fogo no cerrado. II - As queimadas e a dispersão de sementes em algumas espécies anemocóricas do estrato herbáceo-subarbustivo. Boletim de Botânica da Universidade de São Paulo, 5: 5764, 1977.

COUTINHO, L. M. Fire in the ecology of the Brazilian Cerrado. In: GOLDMMER, J.G. ed. Fire in the tropical biota - ecossystem process and global challenges. Ecological Studies Vol 8A. Berlin: Springer-Verlag, 1990.

DIAS, B. F. S. Impactos do Fogo sobre a Biodiversidade do Cerrado. Dep. Ecologia. Brasília: Universidade de Brasília. Notas Técnicas da Disciplina Ecologia do Fogo, 1998.

FIEDLER, N. C. E MEDEIROS, M. B. Plano de prevenção e combate a incêndios florestais para o Parque Nacional da Serra da Canastra. Brasília. Brasília: IBAMA. 75 p. (no prelo).

GILL, M. A. How fires affect biodiversity. In: Conference Fire and Biodiversity: The Effects and Effectiveness of Fire Management. Melbourne. Proceedings...Australia, 1994.

GUEDES, D. M. Resistência das árvores do cerrado ao fogo: papel da casca como isolante térmico. Brasília, UnB, 1993. Dissertação (Mestrado em Ecologia) - Universidade de Brasília, 1993..

HOFFMANN, W. A. Post-burn reproduction of woody plants in a neotropical savanna: the relative importance of sexual and vegetative reproduction. Journal of Applied Ecology, v. 35, p. 422-433, 1998.

KOMAREK, E. V. Lightning and fire ecology in Africa. In: Tall Timbers Fire Ecology Conference 11: 473-509. Proceedings...Cape Town, 1972.

LANDIM, M. F. e HAY, J. D. Impacto do fogo sobre alguns aspectos da biologia reprodutiva de Kielmeyera coriacea Mart. Revista Brasileira de Biologia, v. 56 (1), p. 127-134, 1995.

LÉVI-STRAUSS, C. Tristes Trópicos. São Paulo: Companhia das Letras, 1996.

MEDEIROS, M. B. Manejo de Fogo em Unidades de Conservação do Cerrado. Boletim do Herbário Ezechias Paulo Heringer, v. 10, p. 75-88, 2002a.

MEDEIROS, M. B. Efeitos do fogo nos padrões de rebrotamento em plantas lenhosas, em campo sujo. Brasília: UnB, 2002b, 122p. Tese de Doutorado. Universidade de Brasília, 2002b.

MIDDLETON, B. A.; SANCHEZ-ROJAS, E.; SUEDMEYER, B. et al. Fire in a tropical dry forest of Central America: a natural part of the disturbance regime? Biotropica, v. 29(4): 515-517, 1997.

MIRANDA, H. S.; ROCHA e SILVA, E. P. e MIRANDA, A. C. Comportamento do fogo em queimadas de campo sujo. In: Miranda, H. S.; Saito, C. H. \& Dias, B. F. S. (orgs.). Impactos de Queimadas em Áreas de Cerrado e Restinga. Dep. Ecologia. Brasília: Universidade de Brasília, 1996.

NEPSTAD, D.C.; MOREIRA, A. G. e ALENCAR, A. A. Flames in the Forest: origins, impacts and alternatives to amazonian fires. Brasília: The Pilot Program to Conserv the Brazilian Rain Forest, 1999, 90 p.

PICKETT, S. T. A. e WHITE, P. S. The ecology of natural disturbance and patch dynamics. Academic Press, Inc, 1995.

POSEY, D. A. Manejo de Floresta Secundária, Capoeiras, Campos e Cerrado (Kayapó). In: Ribeiro, D. (ed.). Suma Etnológica Brasileira. Rio de Janeiro: Finep, 1997.

PRINTES, R. C.; SANTOS-SILVA, J. A. e MATTA-MACHADO, R. A invasão do capim-meloso (Melinis minutiflora, Poaceae) no PNSC (MG): causas do seu sucesso e sugestões para manejo. Belo Horizonte: UFMG. Relatório Técnico, 1998.

RAMOS-NETO, M. B. O Parque Nacional das Emas (GO) e o Fogo: Implicações para a Conservação Biológica. São Paulo: USP, 2000. Tese de Doutorado. Universidade de São Paulo, 2000.

ROBBINS, L. E. e MYERS, R. L. Seasonal effects of prescribed burning in Florida: a review. Florida: Tall Timbers Research Station. Miscellaneous Publication. n. 8, 1992.

ROSA, C. M. M. Recuperação pós-fogo do estrato rasteiro de um campo sujo de cerrado. Brasília: UnB, 1990. Dissertação (Mestrado em Ecologia). Universidade de Brasília, 1990.

SAINT-HILAIRE, A. Viagens às Nascentes do Rio São Francisco. São Paulo: EDUSP (re-edição), 1986. 
SAMBUICHI, R. H. R. Efeitos de longo prazo do fogo periódico sobre a fitossociologia da camada lenhosa de um cerrado em Brasília, DF. Brasília: UnB, 1991. Dissertação (Mestrado em Ecologia) - Universidade de Brasília, 1991.

SATO, M. N. e MIRANDA, H. S. Mortalidade de plantas lenhosas do cerrado sensu stricto submetidas a diferentes regimes de queima. In: Miranda, H. S.; Saito, C. H. \& Dias, B. F. S. (orgs.). Impactos de Queimadas em Áreas de Cerrado e Restinga. Dep. Ecologia. Brasília: Universidade de Brasília, 1996.

SCHOLES, R. J. e ARCHER, S. R. Tree-grass interactions in savannas. Annu. Rev. Ecol. Syst. v. 28, p. 517-544, 1997.

SILVA, E. P. R. Efeito do regime de queima na taxa de mortalidade e estrutura da vegetação lenhosa de campo sujo de cerrado. Brasília: UnB, 1999. Dissertação (Mestrado em Ecologia). Universidade de Brasília, 1999.

SOUZA, M. H. A. O. e SOARES, J. J. Brotamento de espécies arbustivas e arbóreas, posteriormente a uma queimada, num cerradão. In: Seminário Regional de Ecologia. Anais..., v. III, p. 263-275, São Carlos, 1983.

STOCKS, B. J. e TROLLOPE, W. S. W. Fire management: principles and options in the forested and savanna regions of the world. In: Crutzen, P. J. \& Goldammer, J. G. (ed.). Fire in the Environment: the Ecological, Atmospheric and Climate Importance of Vegetation Fires. New York: John Wiley \& Sons Ltd, 1993.

VICENTINI, K. R. F. Análise Palinológica de uma Vereda em Cromínia-Go. Brasília: UnB, 1993. Dissertação (Mestrado em Ecologia) - Universidade de Brasília, 1993.

VICENTINI, K. R. F. História do Fogo no Cerrado: uma Análise Palinológica. Brasília: UnB, 1999. Tese (Doutorado em Ecologia) - Universidade de Brasília, 1999.

WHELAN, R. J. The Ecology of Fire. Cambridge: Cambridge University Press, 1997. 346 p. 